\title{
SARS-CoV-2 self-isolation: recommendations for people with a vision impairment
}

\author{
Peter M. Allen $\mathbb{1}^{1,2} \cdot$ Lee Smith ${ }^{1,3}$
}

Received: 31 March 2020 / Revised: 17 April 2020 / Accepted: 20 April 2020 / Published online: 29 April 2020

(c) The Royal College of Ophthalmologists 2020

In March 2020, the World Health Organization (WHO) declared the COVID-19 outbreak a global pandemic. COVID-19 is caused by SARS-CoV-2, a variant of coronavirus. As of 24th March 2020, over 372,700 cases have been diagnosed in 164 countries and areas, resulting in over 16,200 fatalities [1]. Symptoms of infection are usually non-specific, and include fever, cough, and myalgia, with diarrhoea, with or without the subsequent development of dyspnea [2]. Severe cases that include respiratory distress, sepsis, and septic shock have been increasingly reported [3]. Current guidance (31/03/2020) in England to prevent the spread of the SARS-Cov-2 virus is to stay at home and only leave for the following activities: (1) to shop for basic essentials — only when you really need to; (2) to do one form of exercise a day - such as a run, walk or cycle, alone or with other people you live with; (3) for any medical need-for example, to visit a pharmacy or deliver essential supplies to a vulnerable person; and (4) to travel to and from work-but only where this is absolutely necessary. (https://www.nhs.uk/conditions/coronavirus-covid-19/). Such measures will likely influence mental health, physical health, and behaviours relating to health in the entire population. However, without appropriate guidance these potential detrimental outcomes of self-isolation may be amplified in those who have a disability e.g. vision impairment (VI).

$\triangle$ Peter M. Allen

peter.allen@anglia.ac.uk

$\triangle$ Lee Smith

lee.smith@anglia.ac.uk

1 School of Psychology and Sports Science, Anglia Ruskin University, Cambridge, UK

2 Vision and Eye Research Institute, Anglia Ruskin University, Cambridge, UK

3 Cambridge Centre for Sport and Exercise Sciences, Anglia Ruskin University, Cambridge, UK
People with a VI have an increased risk of depression [4]; decreased mobility [5]; and higher rates of poverty than in the general population [6]. Independently and combined these factors have a detrimental impact on both mental and physical health and consequently quality of life [7] and early mortality [8]. These factors may alone increase anxiety among people with VI in relation to being exposed to SARS$\mathrm{CoV}-2$. Moreover, older people with a VI are more likely to experience poor relationships with spouses, children and friends [9] and this may put them at higher risk of detrimental health outcomes as a result of self-isolation. Interestingly, although Desrosiers et al. [10] showed that compared to the normally sighted elderly, the visually impaired elderly experience more restrictions in participation in daily activities and social roles, Lamoureux et al. [11] found that the least restricted domain of participation was socializing. Unfortunately, this will be the domain most affected by self-isolation. Any activity loss caused by self-isolation is likely to be associated with an increased risk of functional [12] and potentially cognitive decline in the elderly [13].

People with VI may be at increased risk owing to difficulties accessing medical help due to their reliance and unavoidable contact with others. This includes reliance on others to help with daily or weekly chores such as food shopping, or people coming to their homes to assist with tasks they are unable to do themselves. During the current pandemic and imposed regulations physical activity is a necessity in order to maintain physical and mental health. People with VI often need a guide during physical activity. Guides generally lead people with low vision by the elbow (https://www.rnib.org.uk/advice/guiding-blind-or-partiallysighted-person). With the recommendation for social distancing then this haptic approach will be impossible if the guide does not live with the person with VI. Self-isolatingspecific guidance tailored for those with a VI to maintain mental and physical health is needed and several additional strategies tailored to this population's needs should be considered. Here we lay out our five key recommendations for policy and stakeholders: 
(1) Self-efficacy is a predictor for determining if someone is more susceptible to feeling socially isolated. Alma et al. [14] highlights the importance of spending resources to support the development of self-efficacy. An accessible online support intervention to build self-efficacy in people with VI to help them cope with self-isolation [15] is recommended.

(2) Shopping is another challenge as general recommendations for those with a VI are to shop with a friend or store employee [16]. These recommendations during the COVID-19 pandemic may have a negative impact on diet of those with VI. A strategy to overcome this is to allow people with VI access to ration packs or priority on online shopping sites.

(3) Tailored physical activity advice or exercise programs (e.g., chair-based exercise, https://www.nhs.uk/live-w ell/exercise/sitting-exercises/) for people with a VI delivered via a regular slot on radio, television or via a podcast is recommended.

(4) Online programs tailored to those with VI to assist in mental health complications arising from self/isolation is warranted (e.g., mindfulness or meditation) [17].

(5) Online support groups, potentially utilising social network platforms, should be set up for those with VI in which regular contact can be made with other people with a VI.

Applying such strategies will likely reduce any detrimental impact of SARS-CoV-2 imposed isolation on the mental and physical health of people with a VI.

\section{Compliance with ethical standards}

Conflict of interest The authors declare that they have no conflict of interest.

Publisher's note Springer Nature remains neutral with regard to jurisdictional claims in published maps and institutional affiliations.

\section{References}

1. World Health Organization. Novel Coronavirus (2019-nCoV) Situation Report - 64. 2020. https://www.who.int/docs/default- source/coronaviruse/situation-reports/20200324-sitrep-64-covid19.pdf?sfvrsn=703b2c40_2. Accessed 25 Mar 2020.

2. Chan JF, Yuan S, Kok KH, To KK, Chu H, Yang J, et al. A familial cluster of pneumonia associated with the 2019 novel coronavirus indicating person-to-person transmission: a study of a family cluster. Lancet. 2020;395:514-23.

3. Wang C, Horby PW, Hayden FG, Gao GF. A novel coronavirus outbreak of global health concern. Lancet. 2020;395:470-3.

4. Evans JR, Fletcher AE, Wormald RP. Depression and anxiety in visually impaired older people. Ophthalmology. 2007;114: 283-8.

5. Crews JE, Chou CF, Zhang X, Zack MM, Saaddine JB. Healthrelated quality of life among people aged 65 years with selfreported visual impairment: findings from the 2006-2010 behavioral risk factor surveillance system. Ophthalmic Epidemiol. 2014;21:287-96.

6. Stone, M. The economic circumstances of people with a visual impairment. London: Thomas Pocklington Trust; 2012.

7. Cacioppo JT, Hawkley LC. Perceived social isolation and cognition. Trends Cogn Sci. 2009;13:447-54.

8. Steptoe A, Shankar A, Demakakos P, Wardle J. Social isolation, loneliness, and all-cause mortality in older men and women. Proc Natl Acad Sci USA. 2013;110:5797-801.

9. Nazroo J, Zimdars A. Social inclusion, social circumstances and the quality of life of visually impaired older people. Occasional paper number 27. London: Thomas Pocklington Trust; 2010.

10. Desrosiers J, Wanet-Defalque MC, Temisjian K, Gresset J, Dubois MF, Renaud J, et al. Participation in daily activities and social roles of older adults with visual impairment. Disabil Rehabil. 2009;31:1227-34.

11. Lamoureux EL, Hassell JB, Keeffe JE. The impact of diabetic retinopathy on participation in daily living. Arch Ophthalmol. 2004;122:84-8.

12. Avlund K, Lund R, Holstein BE, Due P. Social relations as determinant of onset of disability in aging. Arch Gerontol Geriatr. 2004;38:85-99.

13. Rovner BW, Casten RJ, Leiby BE, Tasman WS. Activity loss is associated with cognitive decline in age-related macular degeneration. Alzheimers Dement. 2009;5:12-7.

14. Alma MA, van der Mei SF, Melis-Dankers BJ, van Tilburg TG, Groothoff JW, Suurmeijer TP. Participation of the elderly after vision loss. Disabil Rehabil. 2011;33:63-72.

15. Rees G, Xie J, Chiang PP, Larizza MF, Marella M, Hassell JB, et al. A randomised controlled trial of a self-management programme for low vision implemented in low vision rehabilitation services. Patient Educ Couns. 2015;98:174-81.

16. https://visionaware.org/blog/visually-impaired-now-what/reevalua ting-the-best-way-to-do-my-shopping-as-a-person-who-is-blind/ 12/. Accessed 25 Mar 2020.

17. Nollett CL, Bray N, Bunce C, Casten RJ, Edwards RT, Hegel MT, et al. Depression in visual impairment trial (DEPVIT): a randomized clinical trial of depression treatments in people with low vision. Investig Ophthalmol Vis Sci. 2016;57:4247-54. 